\title{
Timing of initiation of breastfeeding and its determinants at a tertiary hospital in Ghana: a cross-sectional study
}

\author{
Adwoa Pokua Boakye-Yiadom ${ }^{1,2}$, Samuel Blay Nguah ${ }^{1,2^{*}}$, Emmanuel Ameyaw $^{1,2}$, Anthony Enimil ${ }^{1,2}$, \\ Priscilla Naa Lomle Wobil ${ }^{1}$ and Gyikua Plange-Rhule ${ }^{1,2}$
}

\begin{abstract}
Background: Early initiation of breastfeeding (ElBF), breastfeeding within first hour after birth, is known to have major benefits for both the mother and newborn. EIBF rates, however, tends to vary between and within countries. This study set out to determine the prevalence of ElBF at the Komfo Anokye Teaching Hospital (KATH), Kumasi, Ghana, and to evaluate the determinants of EIBF and time to initiation of breastfeeding.

Methods: A cross-sectional study was conducted at the KATH postnatal wards between August and October 2014. Three hundred and eighty-two mothers delivering at KATH were recruited and data on time to initiation of breastfeeding, antenatal, delivery and immediate postnatal periods were collected. Data analyses using both binary and ordinal logistic regressions with stepwise elimination were used to determine the relationship between ElBF and time to initiation of breastfeeding on one side, and the maternal, pregnancy, delivery and neonatal associated factors.

Results: EIBF was done in $39.4 \%$ (95\%Cl: $34.3-44.5)$ of the newborns with breastfeeding initiated between 1 to $6 \mathrm{~h}$ for $19.7 \%, 6$ to $11 \mathrm{~h}$ in $4.8 \%, 11$ to $16 \mathrm{~h}$ in $4.8 \%$ and after $16 \mathrm{~h}$ in $28.5 \%$ of the deliveries. A higher number of antenatal care visits ( $A O R=1.14,95 \% \mathrm{Cl}: 1.04-1.25, p=0.006)$, delivery by caesarean section ( $\mathrm{AOR}=0.07,95 \% \mathrm{Cl}$ : 0.01 $0.79, p=0.031$ ) and infant rooming-in with mother (AOR: 31.67, 95\%Cl: 5.59-179.43, $p<0.001$ ) were significantly and independently associated with EIBF. Factors independently associated with longer time to initiation of breastfeeding were older maternal age $(A O R=1.04,95 \% \mathrm{Cl}: 1.00-1.09, p=0.039)$, Akan ethnicity $(A O R=1.92,95 \% \mathrm{Cl}$ : 1.14-3.22, $p=0.014$ ), first-born child ( $\mathrm{AOR}=2.06,95 \% \mathrm{Cl}: 1.18-3.58, p=0.011)$, mother rooming-in with newborn $(A O R=0.01 .95 \% C l: 0.00-0.02, p<0.001)$, increasing fifth minute APGAR score $(A O R=0.73,95 \% C l: 0.58-0.93, p=$ 0.010 ) and using prelacteals ( $\mathrm{AOR}=2.42,95 \% \mathrm{Cl}: 1.34-4.40, p=0.004$ ).
\end{abstract}

Conclusions: The low EIBF rate and prolonged time to initiation of breastfeeding at a major tertiary health facility is a major concern. Key interventions will need to be implemented at KATH and possibly other tertiary healthcare facilities in Ghana and beyond to improve EIBF rate and time to breastfeeding.

Keywords: Breastfeeding initiation, Neonates, Determinants, early infant breastfeeding

\footnotetext{
* Correspondence: sbngauh@gmail.com

${ }^{1}$ Komfo Anokye Teaching Hospital, Kumasi, Ghana

${ }^{2}$ Kwame Nkrumah University of Science and Technology, Kumasi, Ghana

C The Author(s). 2021 Open Access This article is licensed under a Creative Commons Attribution 4.0 International License, which permits use, sharing, adaptation, distribution and reproduction in any medium or format, as long as you give appropriate credit to the original author(s) and the source, provide a link to the Creative Commons licence, and indicate if changes were made. The images or other third party material in this article are included in the article's Creative Commons licence, unless indicated otherwise in a credit line to the material. If material is not included in the article's Creative Commons licence and your intended use is not permitted by statutory regulation or exceeds the permitted use, you will need to obtain permission directly from the copyright holder. To view a copy of this licence, visit http://creativecommons.org/licenses/by/4.0/. The Creative Commons Public Domain Dedication waiver (http://creativecommons.org/publicdomain/zero/1.0/) applies to the data made available in this article, unless otherwise stated in a credit line to the data.
} 


\section{Introduction}

Breastfeeding is the ideal way of feeding the newborn in the first six months of life for optimal growth and development [1-3]. The World Health Organisation (WHO) recommends that breastfeeding be commenced within the first hour of life, continued exclusively till six months of age when appropriate complementary feeds are added till the child is two completed years old [4]. This recommendation however has had numerous challenges in both developed and underdeveloped countries. Pain, discomfort and physical vulnerability are considered major reasons why mothers in developed countries delay or refuse to breastfeed [5, 6]. In developing countries such as Ghana, the reasons are largely different [7, 8]. Cultural beliefs about breastmilk especially colostrum, the embellishment of prelacteal feeding as well as certain food preferences are largely the reasons why breastfeeding recommendations are not followed. These cultural beliefs include colostrum being "dirty", its role being to pave way for the real milk and thus should to be discarded. Also, water has to be given to newborns as a way of saying "welcome", a traditional way of welcoming visitors in Ghana. Finally, prelacteals and complementary foods are believed to make children stronger [9].

Early Initiation of Breastfeeding (EIBF), the practice of putting the newborn baby to the mothers' breast to feed within one hour of delivery has been recommended by many international agencies including the WHO. Not breastfeeding the infant within an hour but before $24 \mathrm{~h}$ of birth increases the risk of mortality by $40 \%$, while delaying it till after $24 \mathrm{~h}$ increases it by $80 \%$ [10]. Despite these documented benefits, the prevalence of EIBF still remains low worldwide with only $57.6 \%$ of babies delivered worldwide receiving EIBF. This prevalence, however, differs widely from country to county, and region to region. In Africa it can range from as low as $34.7 \%$ in Nigeria [11] to as high as $98.4 \%$ in Angola [12]. These differing prevalence are undoubtedly due to differences in governmental enacted policies, implementation of these policies and other sociocultural practices.

Since the commencement of the recommendation of EIBF, there have been studies aimed at determining the bottlenecks that exist in its implementation. In their secondary analysis of the WHO global survey data done across three continents, Takahashi et al. [12] determined that having a caesarean delivery, developing complications during pregnancy and the absence of clearly written out postnatal and or neonatal guidelines at a hospital may affect the initiation of EIBF. Within countries however, determinants vary. In Nigeria for instance, maternal factors such as multiparity, delivery in a healthcare facility, vaginal delivery, large birth weight of the infant, higher socioeconomic status and coming from certain regions of the country were independently associated with EIBF [11]. These predictors tend to vary but are often not significantly different from region to region. An analysis of the Bangladesh Demographic and Health Survey [13] for instance revealed infant's weight, socioeconomic status, place of delivery and place of residence were not significant predictors of EIBF.

In Ghana, as in many other African countries, there exists direct evidence that exclusive breastfeeding and EIBF saves newborn lives. Karen et al. [14] observed a dose response relationship between increased risk of neonatal death and delay in initiation of breastfeeding for one hour to seven days of life. Ghana, like many other countries, has adapted EIBF as a governmental policy for over two decades now. The EIBF rate however continues to be low despite it showing a steady increase from $46 \%$ in $2003,52 \%$ in 2008 , to $56 \%$ in 2014 [15]. The current status of EIBF in Ghana, like other countries is as a result of a mixture of home and in-hospital deliveries. Evidence shows that $73 \%$ of births in Ghana occur in a hospital, with this proportions being 90\% for the urban and 59\% for the rural settings [15]. Despite the obvious high proportion of babies born in hospitals there exist no documented study detailing the prevalence of EIBF and its determinants in hospital born babies specifically. This study focused on this knowledge gap in a tertiary hospital in Ghana. It further sought to determine both maternal and neonatal factors that are significantly associated with time to initiation of breastfeeding.

\section{Methods}

\section{Study design}

A cross-sectional study conducted at the Maternity Unit and Mother Baby Unit of the Komfo Anokye Teaching Hospital (KATH), a tertiary hospital in Kumasi, Ghana. The study population included newly delivered mothers who had live births and whose infants were alive after $24 \mathrm{~h}$.

\section{Study site}

The study was conducted in two Directorates of KATH, the Obstetrics and Gynaecology (O\&G) Directorates and the Child Health Directorate. KATH is 1200 bed capacity tertiary health facility and the second largest hospital in Ghana. It is located in the second largest city in Ghana, Kumasi [16].

Kumasi is the capital of the Ashanti region, the most populous region and second largest city in Ghana. It is a typical urban city with bustling commercial activities. Traditional and cultural values are held in high esteem with a typical household often encompassing extended family members. These family members often have a huge say in how newborn infants are treated, including 
mode and type of feeding. Like most other places in Ghana, use of antenatal care (ANC) facilities is very high among residents of the city [15].

KATH provides Primary Health Care Services in addition to secondary and tertiary care services. It receives referrals from other hospitals and clinics in the Ashanti and surrounding regions in the middle and northern parts of Ghana. The O\&G Directorate has three (3) main labour wards where about 8000 deliveries are carried out every year, with $34 \%$ of them being delivered by caesarean section. (KATH Performance Review Report 2019 - Unpublished) The O\&G Directorate has three postnatal wards where newly delivered mothers with their babies are sent to after delivery. These postnatal wards can accommodate about 300 mother baby pairs and are manned by midwives with special oversight by doctors. The directorate also has a nursery where babies born to mothers who are unwell to room in with their babies are kept and nursed by midwives.

In the Child Health Directorate the study was done at the Mother and Baby Unit (MBU). MBU serves as a referral centre for sick newborns from the O\&G Directorate and other surrounding health facilities. The MBU is also divided into three units: A High Dependency Unit which caters for newborn referrals that need special care; a Low Birth Weight Unit where all stable LBW infants are kept and given standard health care and a Septic Unit which admits babies up a month of age referred from the outpatient department of KATH and other hospitals. The unit admits about 4500 newborns every year and has a mortality rate of approximately 13\%. (KATH Performance Review Report 2019 Unpublished).

\section{Sample size}

Two factors were considered in determining the sample size for the study. First was the determination of proportion of deliveries that received EIBF. This was estimated to be $59 \%$ based on the national average. Using a precision of 0.075 from the estimate and a confidence limit of 0.95 , a minimum of 165 infant mother pairs was required for the study. Secondly, the sample size was determined taking into cognisance of the determinant of EIBF. To determine a minimum difference in proportion of $0.15 \%$ of the determinants, using a power of $80 \%$, a type I error rate of 5\%, and prevalence of EIBF 59\%, 370 mother infant pairs were to be recruited. Thus the maximum of the two, 370 was considered the optimum sample size for the study.

\section{Study population}

All mothers who delivered at KATH were eligible to be included in the study. However, to be included both baby and mother must be alive after $24 \mathrm{~h}$ and the mother must consent to being included in the study. Due to the peculiarities of the preterm infant, it was decided that the mothers who delivered before 34 completed weeks gestation as determined by a second trimester ultrasound estimation of gestational age be excluded.

\section{Study procedure}

Between August and October 2014, all mothers who delivered at KATH were identified soon after delivery through the hospital's inpatient registry. A systematic random sampling technique was used to select six mothers a day from the approximately 20 deliveries. The mothers were then screened using the inclusion and exclusion criteria. Those who fulfilled all the inclusion criteria and none of the exclusion criteria were approached for consenting after the study procedure has been explained to them. Most of the mothers readily consented to being included in the study but for the rare cases, two in all, where consent was not given, the next mother in the list was approached, screened and consent requested if eligible.

After consenting, a pretested structured questionnaire (please refer to the supplementary files) was administered by face-to-face interviewing of the mothers. The questionnaire was structured into four main parts.

The first part asked about the sociodemographics of the mother. These included the completed age in years, religious affiliation, marital status categorised as single or married, place of residence categorised as rural or urban, highest level of education attained and occupation, categorised as employed or unemployed.

The second section of the questionnaire asked about pregnancy and antenatal factors. These included the number of ANC visits attended before delivery, any medical condition during ANC, parity, mode of delivery and occurrence of postpartum complications. These responses from the mothers were corroborated with that recorded in the maternal and child health record book and their respective medical records. For mothers who delivered via caesarean section the type of anaesthesia given was also recorded.

The third part of the questionnaire asked about neonatal factors including the birth order of the current baby, mother practicing skin-to-skin after delivery and ward on which baby is placed after birth. The ward was recorded as either the baby rooming-in with the mother, sent to the nursery or to the MBU. Other neonatal factors such as the birth weight, which was recorded to one decimal place, the first- and fifth-minute APGAR scores (a score used to rapidly determine the health of newborns at birth) were obtained from the birth records of the child as well as the maternal and child health record book. 
The final section of the questionnaire was directed towards the breastfeeding history of the child. This included finding out if the mother had ever successfully breastfed, the time it took to initiate breastfeeding for the current baby and the administration of prelacteal feed. Time to initiation of breastfeeding was determined by first recording the time of delivery and time baby was put to breast for the first time. In cases where this was missing from the mother's clinical record, it was obtained by interviewing the mothers to give an estimation of the duration between birth and first breastfeeding. For mother who underwent caesarean section, the time to initiation of breastfeeding was obtained from the mother's medical record that usually contains the time of delivery and time baby was put to breast.

\section{Data management and statistical analysis}

Completed questionnaires were doubly entered into a predesigned electronic database using EpiData 3.1 (Odense, Denmark). The two datasets were then compared weekly and cleaned of abnormal or wrongful entries. Upon completion of data collection, the final dataset was exported to STATA 13.1 (StataCorp LP., College Station, TX, USA) for analysis.

Time to initiation of breastfeeding was categorised into four; less than one hour, one to six hours, greater than six hours but less than $16 \mathrm{~h}$ and $16 \mathrm{~h}$ or more. The prevalence of these times was determined with their binomial exact $95 \%$ confidence intervals. Crude association between the maternal sociodemographic, obstetric history, infant characteristics, past and current feeding practices and EIBF was determined and reported initially as the crude odds ratio with their respective 95\% confidence interval. To determine the best fit model for the prediction of EIBF, a backward stepwise logistic regression model with a significance level cut-off for elimination from the model of 0.2 was done with all predictors to start with. After the stepwise elimination of the least predictive dependent variables, the adjusted odd ratios with their confidence intervals were computed using all retained variables.

To determine predictors of time to initiation of breastfeeding an ordered logistic regression was fitted. This was first done for each variable separately to determine crude associations and report as odd ratio with $95 \%$ confidence intervals. Similarly, to determine the best fit model for the predictors of time to initiation of breastfeeding, a backward stepwise ordinal logistic regression model with a significance level cut-off for elimination from the model of 0.2 was done with all predictors to start with. The best fitting model was then reported. For all analysis a two sided $p$-value of $<0.05$ was considered statistically significant.

\section{Results}

In all, 382 mother-infant pairs were recruited for this study but 376 were included in the analysis. The description of the maternal, pregnancy and infant characteristics are as shown in Table 1 . The mean $(+\mathrm{SD})$ age of the mothers was $29( \pm 6.4)$ years. The majority of the mothers were from the local Akan tribe (73.1\%), married (86.7\%), employed (82.7\%), had completed a minimum of secondary schooling $(73.1 \%)$, of the Christian religious faith $(83.2 \%)$ and used the national health insurance (99.5\%). The median (IQR) parity was 3(1-4) and mean $( \pm \mathrm{SD})$ number of ANC visits before delivery was $7.0(+3.1)$. Forty-four $(11.7 \%)$ mothers were known to have a medical condition before delivery while $12(3.2 \%)$ had various postpartum complications. Caesarean section rate was $34.8 \%$. For $30.3 \%$ of the mothers, the current delivery was their first while $34.8 \%$ had never breastfed. Only 27(7.2\%) of the babies were less than 38 completed weeks at the time of delivery. First and fifth minute APGAR scores of three and below were seen in $16(4.3 \%)$ and $4(1.1 \%)$ of the babies respectively. Only $216(57.5 \%)$ of the babies roomed-in with their mothers within the first $24 \mathrm{~h}$ while 110 (29.3\%) were given prelacteal (largely infant formula).

EIBF was done in 39.4\% (95\%CI: 34.3-44.5) of the newborns. The number of newborns who were initiated on breastfeeding in less than an hour, one to less than 6 $\mathrm{h}$, six to less than $16 \mathrm{~h}$, and $16 \mathrm{~h}$ or more after delivery were 148 (39.4, 95\%CI: 34.5-44.4), 74 (19.7, 95\%CI: 16.0-24.0), 47 (12.5, 95\%CI: 9.5-16.3) and 107 (28.5, 95\%CI, 24.1-33.2) respectively.

The maternal factors that were crudely associated with EIBF (Table 2) were increasing maternal age (COR = 0.96, 95\%CI: 0.93-0.99) and mother being married $(\mathrm{COR}=0.50,95 \% \mathrm{CI}: 0.28-0.92)$. None of the pregnancy related variables were crudely associated with EIBF, however, number of ANC visits before delivery showed a marginal clinically significant relationship with EIBF. Neonatal factors that were significantly associated with EIBF were caesarean mode of delivery $(\mathrm{COR}=0.005$, 95\%CI: $0.000-0.037)$, term neonate $(\mathrm{COR}=4.04,95 \% \mathrm{CI}$ : 1.37-11.93), higher birth weight $(\mathrm{COR}=1.57,1.08-$ $2.29)$, infant roomed-in with mother (COR $=106.9$, 95\%CI: 32.9-346.8) and higher five-minute APGAR score $(\mathrm{COR}=1.65,95 \% \mathrm{CI}$ : $1.26-2.17)$. After stepwise removal of insignificant factors and running the final model, higher number of ANC visits (AOR $=1.14$, 95\%CI: $1.04-1.25, p=0.006)$, caesarean mode of delivery $(\mathrm{AOR}=0.07,95 \% \mathrm{CI}: 0.01-0.79, p=0.031)$ and infant rooming-in with mother $(\mathrm{AOR}=31.67$, 95\%VI: 5.59 $179.43, p<0.001)$ were the only three factors significantly associated with EIBF.

Many of the considered factors in this study had a crude association with time to initiation of breastfeeding. 
Table 1 Maternal, pregnancy and infant characteristics of study participants

\begin{tabular}{|c|c|c|c|}
\hline \multicolumn{4}{|l|}{ Maternal Characteristics } \\
\hline & n (\%) & & n (\%) \\
\hline Age in years mean (SD) & $29.0(6.4)$ & Educational status & \\
\hline Ethnicity & & None & $37(9.8)$ \\
\hline Others & $101(26.9)$ & Primary & $21(5.6)$ \\
\hline Akan & $275(73.1)$ & Secondary & $271(72.1)$ \\
\hline Marital Status & & Tertiary & $47(12.5)$ \\
\hline Single & $50(13.3)$ & Employment status & \\
\hline Married & $326(86.7)$ & Unemployed & $65(17.3)$ \\
\hline Residence & & Employed & $311(82.7)$ \\
\hline Rural & $5(1.33)$ & First Baby & \\
\hline Urban & $371(98.7)$ & No & $262(69.7)$ \\
\hline Insurance type & & Yes & $114(30.3)$ \\
\hline Private & $2(0.5)$ & Religion & \\
\hline \multirow[t]{2}{*}{ Government } & $374(99.5)$ & Moslem & $63(16.8)$ \\
\hline & & Christian & $313(83.2)$ \\
\hline \multicolumn{4}{|l|}{ Pregnancy Characteristics } \\
\hline & n (\%) & & n (\%) \\
\hline Medical conditions & & Mode of delivery & \\
\hline No & $332(88.3)$ & Vaginal & $245(65.2)$ \\
\hline Yes & $44(11.7)$ & Caesarean Section & $131(34.8)$ \\
\hline Postpartum complications & & Previously breastfed & \\
\hline No & $364(96.8)$ & No & $263(69.9)$ \\
\hline Yes & $12(3.2)$ & Yes & $113(30.1)$ \\
\hline ANC visits mean (SD) & $7.0(3.1)$ & Parity median (IQR) & $3.0(1.0-4.0)$ \\
\hline \multicolumn{4}{|l|}{ Newborn Characteristics } \\
\hline & n (\%) & & n (\%) \\
\hline Maturity & & Skin to Skin contact done & \\
\hline Preterm & $27(7.2)$ & No & $219(58.2)$ \\
\hline Term & $349(92.8)$ & Yes & $157(41.8)$ \\
\hline Gender & & Where baby was kept & \\
\hline Female & $177(47.1)$ & Roomed In & $216(57.5)$ \\
\hline Male & $199(52.9)$ & Nursery & $94(25.0)$ \\
\hline Prelacteals given & & $\mathrm{MBU}$ & $66(17.5)$ \\
\hline No & $266(70.7)$ & Birth Weight (kgs) mean (SD) & $3.0(0.6)$ \\
\hline Yes & $110(29.3)$ & & \\
\hline First Min. APGAR & & Fifth Min. APGAR & \\
\hline $0-3$ & $16(4.3)$ & $0-3$ & $4(1.1)$ \\
\hline $4-7$ & $246(65.4)$ & $4-7$ & $41(10.9)$ \\
\hline $8-10$ & $114(30.3)$ & $8-10$ & $331(88.0)$ \\
\hline
\end{tabular}

(Table 3) The factors with crude significant association with time to initiation of breastfeeding were maternal age, marital status, employment status of mother, presence of a known medical condition during pregnancy, mode of delivery, presence of post-partum complications, maturity of the newborn, birth weight of the newborn, skin to skin contact practice, newborn rooming-in with mother, administrations of prelacteals, the first minute and fifth minute APGAR scores. After selecting a good fit model and adjusting for all included 
Table 2 Determinants of Early Infant Breastfeeding

\begin{tabular}{|c|c|c|c|c|c|c|}
\hline \multirow[b]{2}{*}{ Characteristic } & \multicolumn{2}{|l|}{ EIBF $n(\%)$} & \multirow[b]{2}{*}{ COR $(95 \% \mathrm{CI})$} & \multirow[b]{2}{*}{ p-value } & \multirow[b]{2}{*}{ AOR $(95 \% \mathrm{Cl})$} & \multirow[b]{2}{*}{ p-value } \\
\hline & No & Yes & & & & \\
\hline Maternal age in years mean (SD) & $29.6(6.5)$ & $27.9(6.1)$ & $0.96(0.93-0.99)$ & 0.013 & $0.95(0.89-1.00)$ & 0.059 \\
\hline Akan ethnicity & $173(75.9)$ & $102(68.9)$ & $0.70(0.44-1.19)$ & 0.138 & & \\
\hline Married & $205(89.9)$ & $121(81.8)$ & $0.50(0.28-0.92)$ & 0.025 & & \\
\hline Urban residence & $225(98.7)$ & $146(98.7)$ & $0.97(0.16-5.90)$ & 0.977 & & \\
\hline Government Insurance use & $226(99.1)$ & $148(100.0)$ & - & - & & \\
\hline Educated mother & $37(9.84)$ & $339(90.2)$ & $0.84(0.42-1.66)$ & 0.611 & $0.41(0.13-1.31)$ & 0.134 \\
\hline Employed mother & $193(84.7)$ & $118(79.7)$ & $0.71(0.42-1.22)$ & 0.219 & & \\
\hline Christian religion & $194(85.1)$ & $119(80.4)$ & $0.72(0.42-1.24)$ & 0.236 & & \\
\hline First born child & $73(32.0)$ & $41(27.7)$ & $0.81(0.52-1.28)$ & 0.374 & & \\
\hline ANC visits done mean (SD) & $6.8(3.1)$ & $7.4(3.2)$ & $1.07(0.99-1.14)$ & 0.056 & $1.14(1.04-1.25)$ & 0.006 \\
\hline Medical conditions in pregnancy & $31(13.6)$ & $13(8.8)$ & $0.61(0.31-1.21)$ & 0.159 & & \\
\hline Parity mean (SD) & $2.7(1.5)$ & $2.7(1.5)$ & $1.01(0.88-1.16)$ & 0.919 & & \\
\hline Caesarean mode of delivery & $130(57.0)$ & $1(0.7)$ & $0.005(0.000-0.037)$ & $<0.001$ & $0.07(0.01-0.79)$ & 0.031 \\
\hline Mother previously breastfed & $72(31.6)$ & $41(27.7)$ & $0.83(0.53-1.31)$ & 0.423 & $0.52(0.24-1.12)$ & 0.097 \\
\hline Post-partum complication present & $12(5.3)$ & $0(0.0)$ & - & - & & \\
\hline Term Infant & $205(89.9)$ & $144(97.3)$ & $4.04(1.37-11.93)$ & 0.012 & & \\
\hline Birth Weight in kgs mean (SD) & $3.0(0.6)$ & $3.1(0.5)$ & $1.57(1.08-2.29)$ & 0.018 & $0.12(0.01-1.13)$ & 0.064 \\
\hline Skin-to-skin contact practiced & $145(63.6)$ & $12(8.1)$ & $0.051(0.03-0.10)$ & $<0.001$ & & \\
\hline Roomed in with mother & $71(31.1)$ & $145(98.1)$ & $106.9(32.9-346.8)$ & $<0.001$ & $31.67(5.59-179.43)$ & $<0.001$ \\
\hline Male infant & $114(50.0)$ & $85(57.4)$ & $1.35(0.89-2.05)$ & 0.159 & & \\
\hline First minute APGAR & $8.1(1.5)$ & $8.6(1.0)$ & $1.16(0.99-1.36)$ & 0.068 & & \\
\hline Fifth minute APGAR & $8.1(1.4)$ & $8.6(0.6)$ & $1.65(1.26-2.17)$ & $<0.001$ & $1.47(0.92-2.33)$ & 0.104 \\
\hline Prelacteals given & $110(48.3)$ & $0(0.0)$ & - & - & & \\
\hline
\end{tabular}

factors, the maternal sociodemographic factors that were significantly associated with time to initiation of breastfeeding were advancing maternal age $(\mathrm{AOR}=1.04$, 95\%CI: $1.00-1.09, p=0.039)$ and coming from the local Akan ethnicity $(\mathrm{AOR}=1.92,95 \% \mathrm{CI}: 1.14-3.22, \quad p=$ 0.014). Pregnancy factors associated with the time to initiation of breastfeeding were neonate being the first born $(\mathrm{AOR}=2.06,95 \% \mathrm{CI}: 1.18-3.58, p=0.011)$. Neonatal factors associated with time to initiation of breastfeeding were rooming-in the child with the mother $(\mathrm{AOR}=0.01$. 95\%CI: $0.00-0.02, p<0.001)$ and the giving of prelacteal $(\mathrm{AOR}=2.42$, 95\%CI: 1.34-4.40, $p=0.004)$ and higher five-minute APGAR scores $(\mathrm{AOR}=0.73$, 95\%CI: $0.58-$ 0.93. $p=0.010)$.

\section{Discussion}

In this study, we set out to estimate the rate or EIBF, determinants of EIBF and determinants of time to initiation of breastfeeding in a major tertiary hospital in Ghana. The EIBF rate among babies delivered at $\mathrm{KATH}$ of $39.4 \%$ is quite low compared the national average of $56 \%$. Factors that independently predicted the practice of EIBF were delivery per vagina, higher number of ANC visits by the mother before delivery and mother infant pair rooming-in together. Determinants of time to initiation of breastfeeding however included maternal age, ethnicity, birth order of the neonate, mother infant pair rooming-in together, administration of prelacteals (infant milk formulas) to the newborn and higher fiveminute APGAR scores.

$\mathrm{KATH}$ is a major referral centre in the northern sector of Ghana, implying a higher proportion of mothers delivering at KATH would have complicated pregnancies compared the national proportion. This assertion is supported by the very high proportion of caesarean sections and mothers with pregnancy related medical conditions in our study. The structure of our study population could be the major reason for this large difference between the in-hospital and national EIBF rates. Though there is enough evidence that EIBF rates tend to vary in this manner, both within the West African sub region and beyond, [12] it is also evident that some practices within $\mathrm{KATH}$ may contribute significantly to the low EIBF rate. With such a low proportion of newborns rooming-in with their mothers and the high occurrence of use of prelacteal, it is not surprising that the EIBF rate 
Table 3 Determinants of time to initiation of breastfeeding

\begin{tabular}{|c|c|c|c|c|}
\hline Characteristic & COR $(95 \% \mathrm{Cl})$ & p-value & AOR $(95 \% \mathrm{Cl})$ & p-value \\
\hline Maternal age in years & $1.04(1.01-1.07)$ & 0.003 & $1.04(1.00-1.09)$ & 0.039 \\
\hline Akan ethnicity & $1.44(0.95-2.19)$ & 0.087 & $1.92(1.14-3.22)$ & 0.014 \\
\hline Married & $2.15(1.23-3.76)$ & 0.007 & & \\
\hline Urban residence & $0.72(0.14-3.84)$ & 0.701 & & \\
\hline Government Insurance use & $0.35(0.03-4.25)$ & 0.413 & & \\
\hline Educated mother & $1.02(0.54-1.92)$ & 0.961 & & \\
\hline Employed mother & $1.63(1.00-2.64)$ & 0.049 & & \\
\hline Christian religion & $1.56(0.95-2.55)$ & 0.078 & & \\
\hline First born child & $1.14(0.77-1.70)$ & 0.507 & $2.06(1.18-3.58)$ & 0.011 \\
\hline ANC visits done & $0.95(0.90-1.01)$ & 0.120 & & \\
\hline Medical conditions in pregnancy & $2.59(1.40-4.77)$ & 0.002 & $1.91(0.96-3.82)$ & 0.065 \\
\hline Parity & $0.97(0.85-1.10)$ & 0.612 & & \\
\hline Caesarean section delivery & $34.9(20.4-59.5)$ & $<0.001$ & & \\
\hline Mother previously breastfed & $1.09(0.73-1.62)$ & 0.675 & & \\
\hline Post-partum complication present & $3.08(1.11-8.61)$ & 0.031 & & \\
\hline Term Infant & $0.14(0.06-0.33)$ & $<0.001$ & & \\
\hline Birth weight & $0.56(0.4-0.78)$ & 0.001 & & \\
\hline Skin-to-skin contact practiced & $24.5(14.9-40.2)$ & $<0.001$ & & \\
\hline Roomed in with mother & $0.01(0.00-0.01)$ & $<0.001$ & $0.01(0.00-0.02)$ & $<0.001$ \\
\hline Male infant & $0.80(0.55-1.16)$ & 0.240 & & \\
\hline First minute APGAR & $0.82(0.72-0.94)$ & 0.006 & & \\
\hline Fifth minute APGAR & $0.63(0.52-0.76)$ & $<0.001$ & $0.73(0.58-0.93)$ & 0.010 \\
\hline Prelacteals given & $9.66(6.18-15.10)$ & $<0.001$ & $2.42(1.34-4.40)$ & 0.004 \\
\hline
\end{tabular}

is low. The Baby Friendly Hospital Initiative, [4] when adopted, is expected to promote EIBF among mothers in all hospitals. After adoption and implementation of these ten steps to becoming Baby Friendly, some high level care hospitals, even in developed countries, have markedly improved their EIBF rate [17]. To improve the EIBF status therefore requires a whole paradigm shift in managing mothers and infants before, during and after delivery.

In our study, the main determinant of EIBF was rooming-in, a major component of the Baby Friendly Hospital Initiative. However, there were other notable determinants of not receiving EIBF namely; caesarean mode of delivery and lower number of ANC visits before delivery. It is of little doubt that both physical and psychological trauma associated with caesarean delivery before, during and after pregnancy can be a big disincentive for EIBF. Worldwide, caesarean section delivery has been a consistent significant independent factor associated with decreased practice of EIBF [11, 12, 18]. Complications to both the mother and newborn infants make this group a high risk group. However, $\mathrm{KATH}$, and for that matter major health institutions in Ghana can improve EIBF rate if proper feeding practices are aggressively adapted by healthcare personnel after caesarean section deliveries and mothers are supported enough by the midwives/health staff to initiate breastfeeding early. Considering the fact that caesarean section deliveries rate in our study was approximately $35 \%$, and all but two mothers had spinal anaesthesia, implementing interventions such as early skin to skin contact and immediate putting of the baby to the breast are likely to improve the EIBF rate significantly in many health institutions [19].

In Ghana, the nurses and midwives consistently educate prospective mothers on the need and benefits of EIBF and breastfeeding in general at every ANC visits. Therefore, it is not surprising that higher number of ANC visits in our study is associated with EIBF. This is irrespective of the fact that Ghana has adapted the WHO policy on breastfeeding with no central regulation nor specific incentives given to the mothers to breastfeed. This is indeed an observed phenomenon in many studies from places where similar messages are taught to the mothers at every ANC visit [20,21]. Current literature however indicates a mixed conclusion concerning the association between the number of ANC visits and EIBF [13]. Studies that do not show a relationship 
between EIBF and number of ANC visits often reveal inconsistent or no education by healthcare persons during routine visits [22].

Inasmuch as EIBF is recommended because of its well documented benefits there will be conditions under which it might not be possible to achieve. More than a quarter $(28.5 \%)$ of the newborns in our study were breastfed for the first time after $16 \mathrm{~h}$. At first glance this observation could be attributed to the clinical states of the mothers, such as maternal illness before, at and after delivery as well as the infant's clinical states after delivery including the APGAR score. However, modifiable factors such as infant rooming-in with mother and the administering of prelacteal are seen as stronger determinants of longer time to breastfeeding.

These observations underpin the fact that a greater emphasis on antenatal education on the effects and benefits of breastfeeding, an intervention with a proven success rate even in countries with very limited exclusive and breastfeeding rate must be encouraged and implemented at health institutions in Ghana. Secondly, inhospital modifiable factors such as baby rooming-in with mother and discouraging the use of prelacteal, all of which are component of the Baby Friendly Hospital Initiative, when implemented should help reduce time to breastfeeding.

\section{Limitations}

Despite the obvious strength of our study in term of being carried out in a large hospital with a high number of babies born, there are some notable limitations. First, the time of breastfeeding was obtained from recall by the mothers. This invariably introduces recall bias. Secondly, the clinical setting of our study may be very different from what pertains in many of other rural areas in Ghana, thus making the finding and wholesale application of the recommendations problematic in these areas. Finally, this was a single centre study therefore limiting its generalisability to other tertiary hospitals.

\section{Conclusion}

More than a third (39.4\%) of babies born at KATH benefited from EIBF but as many as $23.3 \%$ of them were breastfed after $16 \mathrm{~h}$ from delivery. Independent factors significantly associated with EIBF were increasing number of ANC visits, vaginal mode of delivery compared to caesarean delivery and rooming-in mother and baby. The determinants associated with longer time to initiating breastfeeding were increasing maternal age, coming from the Akan ethnic group and infant being a first born. Other significantly associated risk factors include mother and infant not rooming-in together after delivery, higher fifth minute APGAR scores and giving prelacteal feeds to the baby.

\section{Supplementary Information}

The online version contains supplementary material available at https://doi. org/10.1186/s12884-021-03943-x.

\section{Additional file 1}

\section{Acknowledgements}

We acknowledge the immense contribution to the success of the project made by the nurses at the KATH labour ward and mother baby units. We are also grateful to the mothers who willingly consented to be part of this research.

\section{Authors' contributions}

APB, PNLW and GPR conceptualised, designed and collected data for the study. APB, AnE and SBN were involved in managing, cleaning, analysis and interpretation of the data. SBN, APB and EmA drafted the initial manuscript. All authors made inputs and approved the final manuscript.

\section{Funding}

This research did not receive any specific grant from funding agencies in the public, commercial, or not-for-profit sectors.

\section{Availability of data and materials}

The datasets generated and/or analysed during the current study are available in the Mendeley repository available at https://data.mendeley.com/ datasets/y9h89fvfwf/1

\section{Declarations}

Ethics approval and consent to participate

Ethical clearance for the study was obtained from the Committee on Human Research, Publications and Ethics of Kwame Nkrumah University of Science and Technology in Kumasi which approved all methods in this study. All protocols were carried out in accordance with relevant guidelines and regulations. An informed consent was obtained from the all participants for the study. All participants knew that participating in the study was voluntary and they could decide to discontinue participation any time, if they so wished without any consequences to their baby and/or themselves. All participants were delinked from their clinical data and identified by study identification numbers.

Consent for publication

Not applicable.

\section{Competing interests}

The authors declare that they have no competing interests.

Received: 9 November 2020 Accepted: 8 June 2021

Published online: 30 June 2021

\section{References}

1. W.H.O. Exclusive breastfeeding for six months best for babies everywhere. 5th January statement. 2011;:http://www.who.int/mediacentre/news/sta tements/201. http://www.who.int/mediacentre/news/statements/2011/brea stfeeding_20110115/en/. Accessed 30 August 2020.

2. Langa L. Breast is always best, even for HIV-positive mothers. Bull World Health Organ. 2010;88(1):9-10. https://doi.org/10.2471/blt.10.030110.

3. WHO. WHO | Global Strategy: Breastfeeding critical for child survival. Who. 2010. https://www.who.int/mediacentre/news/releases/2004/pr19/en/. Accessed 30 August 2020.

4. WHO. Infant and young child nutrition: Global strategy on infant and young child feeding. Fifty Fifth World Heal Assem. 2002;53 April:1-18. http://apps. who.int/gb/archive/pdf_files/WHA55/ea5515.pdf. Accessed 22 September 2020.

5. Kelleher CM. The physical challenges of early breastfeeding. Soc Sci Med. 2006;63(10):2727-38. https://doi.org/10.1016/j.socscimed.2006.06.027.

6. Ogbuanu CA, Probst J, Laditka SB, Liu J, Baek JD, Glover S. Reasons why women do not initiate breastfeeding. A southeastern state study. Women's Heal Issues. 2009;19(4):268-78. https://doi.org/10.1016/j.whi.2009.03.005. 
7. Aborigo RA, Moyer CA, Rominski S, Adongo P, Williams J, Logonia G, et al. Infant nutrition in the first seven days of life in rural northern Ghana. BMC Pregnancy Childbirth. 2012;12(1). https://doi.org/10.1186/1471-2393-12-76.

8. Da Silva MC, Gunnlaugsson G, Smedman L. Determinants of delayed initiation of breastfeeding: a community and hospital study from GuineaBissau. Int J Epidemiol. 1992;21(5):935-40. https://doi.org/10.1093/ije/21.5.935.

9. Joyce N. Socio-cultural factors influencing exclusive breastfeeding practices among women in the Bawku West District, Ghana University of Ghana. 2017. http://ugspace.ug.edu.gh.

10. Edmond K, Newton S, Hurt L, Shannon CS, Kirkwood BR, Mazumder S, et al. Timing of initiation, patterns of breastfeeding, and infant survival: prospective analysis of pooled data from three randomised trials. Lancet Glob Heal. 2016;4(4):e266-75. https://doi.org/10.1016/S2214-109X(16)0004 $0-1$.

11. Berde AS, Yalcin SS. Determinants of early initiation of breastfeeding in Nigeria: a population-based study using the 2013 demograhic and health survey data. BMC Pregnancy Childbirth. 2016;16(1):1-9. https://doi.org/10.11 86/s12884-016-0818-y.

12. Takahashi K, Ganchimeg T, Ota E, Vogel JP, Souza JP, Laopaiboon M, et al. Prevalence of early initiation of breastfeeding and determinants of delayed initiation of breastfeeding: secondary analysis of the WHO global survey. Sci Rep. 2017;7(1). https://doi.org/10.1038/srep44868.

13. Karim F, Salam Khan AN, Tasnim F, Kabir Chowdhury MA, Billah SM, Karim T, et al. Prevalence and determinants of initiation of breastfeeding within one hour of birth: an analysis of the Bangladesh demographic and health survey, 2014. PLoS One. 2019;14(7):e0220224. https://doi.org/10.1371/journal. pone.0220224

14. Edmond KM, Zandoh C, Quigley MA, Amenga-Etego S, Owusu-Agyei S, Kirkwood BR. Delayed breastfeeding initiation increases risk of neonatal mortality. Pediatrics. 2006;117(3):e380-6. https://doi.org/10.1542/peds.2 005-1496.

15. GSS. 2014 Demographic and Health Survey Fact Sheet Ghana. Report. 2014;: 2. http://dhsprogram.com/pubs/pdf/GF36/GF36.pdf. Accessed 31 August 2020.

16. Komfo Anokye Teaching Hospital. Komfo Anokye Teaching Hospital | "A Centre of Excellence." 2019. http://www.kathhsp.org/. .

17. Pérez-Escamilla R, Martinez JL, Segura-Pérez S. Impact of the baby-friendly Hospital initiative on breastfeeding and child health outcomes: a systematic review. Matern Child Nutr. 2016;12(3):402-17. https://doi.org/10.1111/ men.12294.

18. John JR, Mistry SK, Kebede G, Manohar N, Arora A. Determinants of early initiation of breastfeeding in Ethiopia: a population-based study using the 2016 demographic and health survey data. BMC Pregnancy Childbirth. 2019; 19(1):69. https://doi.org/10.1186/s12884-019-2211-0.

19. Dudeja S, Sikka P, Jain K, Suri V, Kumar P. Improving first-hour breastfeeding initiation rate after cesarean deliveries: a quality improvement study. Indian Pediatr. 2018;55(9):761-4. https://doi.org/10.1007/s13312-018-1376-3.

20. Vieira TO, Vieira GO, Giugliani ERJ, Mendes CM, Martins CC, Silva LR. Determinants of breastfeeding initiation within the first hour of life in a Brazilian population: cross-sectional study. BMC Public Health. 2010;10(1). https://doi.org/10.1186/1471-2458-10-760.

21. Ahmad MO, Sughra U, Kalsoom U, Imran M, Hadi U. Effect of antenata counselling on exclusive breastfeeding. J Ayub Med Coll Abbottabad. 2012; 24:116-9 http://www.ayubmed.edu.pk/JAMC/24-2/Owais.pdf. .

22. Dhandapany G, Bethou A, Arunagirinathan A, Ananthakrishnan S. Antenatal counseling on breastfeeding - is it adequate? A descriptive study from Pondicherry, India. Int Breastfeed J. 2008;3(1):5. https://doi.org/10.1186/174 6-4358-3-5.

\section{Publisher's Note}

Springer Nature remains neutral with regard to jurisdictional claims in published maps and institutional affiliations.

Ready to submit your research? Choose BMC and benefit from:

- fast, convenient online submission

- thorough peer review by experienced researchers in your field

- rapid publication on acceptance

- support for research data, including large and complex data types

- gold Open Access which fosters wider collaboration and increased citations

- maximum visibility for your research: over $100 \mathrm{M}$ website views per year

At BMC, research is always in progress.

Learn more biomedcentral.com/submissions 